\title{
Is MLC phosphorylation essential for the recovery from ROCK inhibition in glioma $\mathrm{C} 6$ cells?
}

\author{
Jarosław Korczyński', Katarzyna Sobierajska², Patryk Krzemiński³ , Anna Wasik1, \\ Dorota Wypych'1, Paweł Pomorski1 and Wanda Kłopocka ${ }^{\circledR}$
}

${ }^{1}$ Nencki Institute of Experimental Biology, Polish Academy of Sciences, Warszawa, Poland; ${ }^{2}$ Medical University of Lodz, Łódź, Poland; ${ }^{3}$ Centro de Investigación del Cáncer, CSIC-University of Salamanca, Spain

\begin{abstract}
Inhibition of Rho-associated protein kinase (ROCK) activity in glioma $\mathrm{C} 6$ cells induces changes in actin cytoskeleton organization and cell morphology similar to those observed in other types of cells with inhibited RhoA/ ROCK signaling pathway. We show that phosphorylation of myosin light chains (MLC) induced by $\mathrm{P} 2 \mathrm{Y}_{2}$ receptor stimulation in cells with blocked ROCK correlates in time with actin cytoskeleton reorganization, F-actin redistribution and stress fibers assembly followed by recovery of normal cell morphology. Presented results indicate that myosin light-chain kinase (MLCK) is responsible for the observed phosphorylation of MLC. We also found that the changes induced by $\mathrm{P}_{2} \mathrm{Y}_{2}$ stimulation in actin cytoskeleton dynamics and morphology of cells with inhibited ROCK, but not in the level of phosphorylated MLC, depend on the presence of calcium in the cell environment.
\end{abstract}

Keywords: actin, calcium signaling, myosin II, MLC phosphorylation RhoA

Received: 16 November, 2010; revised: 09 December, 2010; accepted: 10 December, 2010; available on-line: 07 March, 2011

\section{INTRODUCTION}

The Rho family members: RhoA, Rac1 and Cdc42 are crucial regulators of actin cytoskeleton dynamics. Thus they control cell shape, adhesion and contractility that drive cell migration. RhoA mediates reorganization of actin filamentous network by involving several downstream effectors (Schmitz et al., 2000; Tsuji et al., 2002). Among them is the serine-threonine protein kinase (ROCK). ROCK phosphorylates several actin-binding proteins (Riento \& Ridley, 2003). ROCK acts upon LIM kinase (LIMK) and testis-specific kinase (TESK), which in turn phosphorylate and inactivate cofilin (Arber et al., 1998; Maekawa, 1999; Bernard, 2007; Pak et al., 2008). ROCK can also control the activity of myosin II indirectly, by phosphorylation of the myosin-binding subunit of myosin light chain (MLC) phosphatase in this way inhibiting MLC dephosphorylation (Kimura et al., 1996; Hartshorne, 1998; Kawano et al., 1999), as well as directly, by phosphorylating serine 19 of myosin regulatory light chain (Amano et al., 1996; Riento \& Ridley, 2003; Matsumura, 2005).

The RhoA/ROCK-mediated increase in the level of phosphorylated MLC and contraction occurs in the absence of calcium transients (Kimura et al., 1996), while myosin light chain kinase (MLCK) phosphorylates MLC in a $\mathrm{Ca}^{2+}$-dependent way (Katoh et al., 2001). These two kinases may play distinct roles in the spatial regulation of myosin II activity. The RhoA/ROCK signaling pathway plays an important role in generating myosin II-based contractility in the center of the cell (Chrzanowska-Wodnicka \& Burridge, 1996; Kimura et al., 1996; Kawano et al., 1999; Totsukawa et al., 2000) that is needed for a cell adhesion and tail retraction during migration (Worthylake et al., 2001). The MLCK regulation by $\mathrm{Ca}^{2+} /$ calmodulin is primarily responsible for phosphorylating MLC at the cell periphery (Totsukawa et al., 2000). MLC phosphorylation and subsequent myosin II activation is necessary to induce the assembly of stress fibers and focal adhesions in non-muscle cells.

P2Y receptors are metabotropic G protein-coupled receptors activated by purine and/or pyrimidine nucleotides. They trigger potent and diverse cellular responses through activation of different signaling pathways that are dependent on the type of the $G \alpha$ subunit. Activation of $\mathrm{G} \alpha_{\mathrm{a}}$-coupled $\mathrm{P} 2 \mathrm{Y}_{2}$ receptor by uridine 5'-triphosphate (UTP) or adenosine 5 '-triphosphate (ATP) initiates a PLC $\beta$-dependent inositol 1,4,5-trisphosphate $\left(\mathrm{IP}_{3}\right)$ cascade followed by calcium release from intracellular stores via $\mathrm{IP}_{3}$ receptor. In nonexcitable cells the calcium response is biphasic and consists of $\mathrm{Ca}^{2+}$ release from the endoplasmic reticulum (ER) followed by calcium influx from extracellular space known as capacitative calcium entry (Putney, 1986; Berridge, 1995; Clapham, 1995). Rat C6 glioma cells are nonexcitable transformed glial cells that express $\mathrm{P} 2 \mathrm{Y}_{2}$ receptors and respond to both ATP and UTP equally. The stimulation of these receptors initiates a biphasic $\mathrm{Ca}^{2+}$ response compatible with the typical capacitative model of calcium influx (Baranska et al., 1999; Sabala et al., 2001; Czajkowski et al., 2002).

The calcium mobilization mediated by $\mathrm{G} \alpha_{\mathrm{q}}$-coupled receptors promotes actin cytoskeleton reorganization by triggering different signaling pathways, including activation of calcium-dependent myosin light chain kinase (Katoh et al., 2001). Other signal transduction pathways activated by stimulation of $\mathrm{P}_{2} \mathrm{Y}_{2}$ receptor have been proposed following the observation that $\mathrm{P} 2 \mathrm{Y}_{2}$ receptors can bind to membrane proteins and change $G \alpha$ affinity. $\mathrm{P} 2 \mathrm{Y}_{2}$ receptors contain an integrin-binding motif (RGD) that facilitates interaction with $\alpha_{\mathrm{v}} \beta_{3}$ or $\alpha_{\mathrm{v}} \beta_{5}$ integrins (Erb et al., 2001) that modulate receptor coupling to specific $\mathrm{G}$ proteins $\mathrm{G} \alpha_{12 / 13}$ and $\mathrm{G} \alpha_{\mathrm{o}}$. These proteins in turn ac-

W.klopocka@nencki.gov.pl

Abbreviations: ER, endoplasmic reticulum; MLC, myosin light chains; ROCK, Rho-associated protein kinase; PBS, phosphate-buffered saline; TBST buffer, Tris buffer, saline, Tween-20 
tivate RhoA and Rac1, respectively (Sauzeau et al., 2000; Erb et al., 2006; Singh et al., 2007).

Previously we have shown that changes in F-actin distribution and cell morphology caused by inhibition of ROCK activity in glioma C6 cells are reversed immediately after $\mathrm{P} 2 \mathrm{Y}_{2}$ receptor stimulation with ATP (Targos et al., 2006). Since myosin II is an important effector in RhoA/ROCK-controled an actin cytoskeleton organization, the aim of this work was to determine whether MLC phosphorylation is essential for the recovery of cells induced by $\mathrm{P}_{2} \mathrm{Y}_{2}$ receptor stimulation. The influence of $\mathrm{P} 2 \mathrm{Y}_{2}$ receptor stimulation with UTP on the level of phosphorylated MLC (P-MLC) was investigated in glioma C6 cells under various experimental conditions. UTP is the ligand of choice, since it is a strong stimulator of $\mathrm{P} 2 \mathrm{Y}_{2}$ receptor and unlike ATP, it is not metabolized by ectoenzymes to produce several metabolites, like ADP and adenosine, that are able to stimulate other nucleotide receptors: $\mathrm{P} 2 \mathrm{Y}_{1}, \mathrm{P} 2 \mathrm{Y}_{12}, \mathrm{P}_{2} \mathrm{Y}_{13}$ and $\mathrm{P} 1$ present in glioma C6 cells (Sabala et al., 2001; Czajkowski \& Baranska, 2002; Baranska et al., 2004; Suplat et al., 2007).

In the present paper we show that: 1 . UTP stimulation leads to MLC phosphorylation in glioma C6 cells with inhibited ROCK regardless of calcium conditions. 2. The activation of myosin II in cells with blocked ROCK temporally correlates with reorganization of actin cytoskeleton and recovery of normal cell morphology only in culture medium. 3. In calcium-free medium MLC phosphorylation after UTP stimulation of $\mathrm{P}_{2} \mathrm{Y}_{2}$ receptor is not sufficient for cell recovery from ROCK inhibition. 4. Inhibition of MLCK activity reduces MLC phosphorylation precludes cell recovery.

\section{MATERIALS AND METHODS}

Reagents and antibodies. Inhibitors Y-27632 and ML-7, UTP, bovine serum albumin (BSA) and Ripa buffer were obtained from Sigma Aldrich. Complete, EDTA-free Protease Inhibitor Cocktail was from Roche and SuperSignal West Pico Chemiluminescent Substrate for detecting signal in Western blot analysis was from Thermo Scientific. Triton X-100 was from Roth Chemicals. MLC1 and P-MLC (phospho S20) primary antibodies and anti-rabbit peroxidase-conjugated secondary antibody for Western blot were from Abcam. Fura-2 AM, anti-rabbit secondary antibodies conjugated with Alexa 488, and Alexa 546-conjugated phalloidin were from Invitrogen. Dulbecco's modified Eagle's medium (DMEM), newborn calf serum (NCS), and fetal bovine serum (FBS) were from Gibco BRL.

Cell culture and treatment. Rat glioma C6 cells were cultured as described previously (Suplat et al., 2007; Suplat-Wypych et al., 2010). For immunofluorescence analysis and calcium measurements cells were seeded onto cover slips and cultivated for 2 days. For Western blot experiments cells were cultured in $10 \mathrm{~cm}$ Petri dishes to $80 \%$ confluence. Before cell fixation for immunofluorescence staining or material collection for Western blot analysis cells were pretreated, depending on the configuration, with: Ctrl UTP — stimulation with $100 \mu \mathrm{M}$ UTP for $2 \mathrm{~min}$, Ctrl ML-7 UTP — incubation with $10 \mu \mathrm{M}$ ML-7 for $30 \mathrm{~min}$ followed by UTP stimulation, Ctrl - $\mathrm{Ca}^{2+}$ UTP - stimulation with UTP in calcium-free medium (containing EGTA), Ctrl $-\mathrm{Ca}^{2+} \mathrm{UTP}+\mathrm{Ca}^{2+}$ - for evoked biphasic calcium response cells were first stimulated with UTP in calcium- free medium and $5 \mathrm{~min}$ later the medium was replaced for 2 min with a normal medium, Y - incubation with $100 \mu \mathrm{M}$ Y-27632 for $30 \mathrm{~min}, \mathrm{Y}$ UTP — incubation with Y-27632 followed by UTP stimulation, Y ML-7 UTP — incubation with $10 \mu \mathrm{M}$ ML-7 together with $100 \mu \mathrm{M}$ Y-27632 for $30 \mathrm{~min}$ followed by UTP stimulation, Y $-\mathrm{Ca}^{2+}$ UTP - incubation with Y-27632 followed by UTP stimulation in calcium-free medium, $\mathrm{Y}-\mathrm{Ca}^{2+} \mathrm{UTP}+\mathrm{Ca}^{2+}$ - after incubation with Y-27632 cells were treated as in the Ctrl $-\mathrm{Ca}^{2+} \mathrm{UTP}+\mathrm{Ca}^{2+}$ configuration.

Immunofluorescence staining. Incubation of cells with proper reagents (see Cell culture and treatment) was terminated by washing with cold PBS. Then cells were fixed with $4 \%$ paraformaldehyde for $30 \mathrm{~min}$, washed with PBS three times, permeabilized with $0.1 \%$ Triton X-100 for $1 \mathrm{~min}$, washed with PBS three times, and then blocked with $1 \%$ bovine serum albumin (BSA) for $1 \mathrm{~h}$ at room temperature (room temp.). Incubation with primary antibodies diluted in PBS with $1 \%$ BSA (P-MLC, 1:200) was carried out at room temp. for $1 \mathrm{~h}$. Cells were then washed three times with PBS with $1 \%$ BSA before incubating with the appropriate secondary antibodies for $1 \mathrm{~h}$ at $37^{\circ} \mathrm{C}$ (anti-rabbit conjugated with Alexa 488, 1:200). Then cells were washed three times with PBS and stained with Alexa 546-conjugated phalloidin diluted in PBS $(1: 200)$ for $30 \mathrm{~min}$ at room temp. Stained cells were washed three times in PBS before mounting on slides.

Image acquisition and analysis. All fluorescence images were acquired on a Leica TCS SP5 laser scanning confocal microscope with a $63 \times(1.4 \mathrm{NA})$ PlanApo objective. For excitation of Alexa 488, Argon laser was used $(488 \mathrm{~nm})$ and fluorescence emission was detected at 500-550 nm. Alexa 546-conjugated phalloidin was excited with DPSS diode laser $(561 \mathrm{~nm})$ and detected at 550-620 nm. Images were converted to 8-bit tiff files. For fluorescence intensity evaluation at least 10 cells from each experiment were analyzed using LAS AF software (Leica Microsystems).

Western blot analysis. For Western blot experiments, glioma C6 cells were incubated with a proper reagents (see Cell culture and treatment) and the incubation was terminated by washing cells with ice-cold PBS. For efficient lysis, cells were scraped from the bottom of culture dishes in the presence of commercial Ripa buffer with Complete (one tablet for $7 \mathrm{ml}$ of Ripa buffer). After $30 \mathrm{~min}$ of incubation in the lysis buffer, cell extracts were centrifuged at 10000 r.p.m. for $15 \mathrm{~min}$ at $4^{\circ} \mathrm{C}$ and the supernatant was boiled in $5 \times$ reducing sample buffer for 5 min. Protein content in cell extracts was determined using the method of Bradford (1976) and $30 \mu \mathrm{g}$ of protein was loaded onto a $12 \%$ SDS/PAGE gel. For immunoblotting, PVDF membranes were blocked with $2 \%$ BSA diluted in TBST buffer and then incubated with anti-P-MLC (1:5000 dilution) or anti-MLC1 antibody $(1: 1000 \mathrm{di}-$ lution), followed by incubation with peroxidase-conjugated secondary antibody (1:10000 dilution) and finally detected using SuperSignal West Pico Chemiluminescent Substrate. Quantitative measurement of optical density in Western blots was conducted using ImageJ program (http://rsb.info.nih.gov/ij/).

Measurement of intracellular calcium. Intracellular calcium was measured under fluorescence microscope as described by Suplat-Wypych et al. (2010). Briefly, $30 \mathrm{~min}$ before calcium measurements, cells on cover slips were washed once with PBS and once with a solution containing: $137 \mathrm{mM} \mathrm{NaCl}, 2.7 \mathrm{mM}$ 

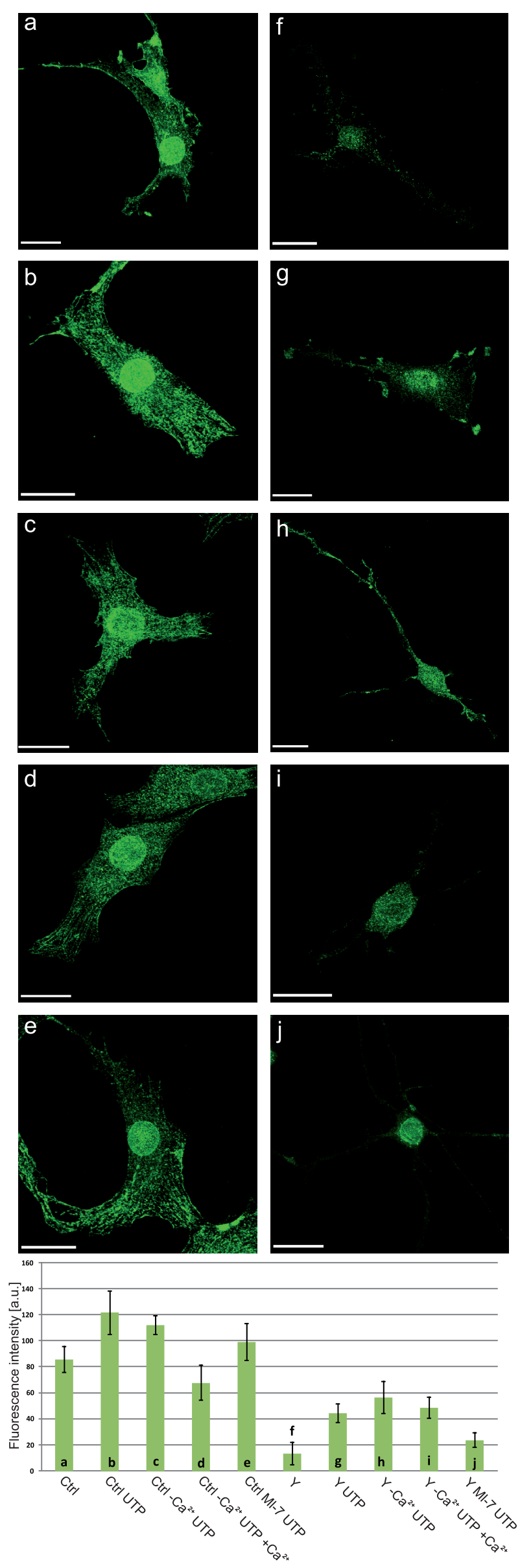

$\mathrm{KCl}, 1 \mathrm{mM} \mathrm{Na} \mathrm{HPO}_{4}, 25 \mathrm{mM}$ glucose, $20 \mathrm{mM}$ Hepes (pH 7.4), $1 \mathrm{mM} \mathrm{MgCl}_{2}, 1 \%$ bovine serum albumin and $2 \mathrm{mM} \mathrm{CaCl}_{2}$ (standard buffer). In experiments performed in the absence of external $\mathrm{Ca}^{2+}, 0.5 \mathrm{mM}$ EGTA was added instead of $2 \mathrm{mM} \mathrm{CaCl}_{2}$. The cells were then incubated at $37^{\circ} \mathrm{C}$ for $30 \mathrm{~min}$ in the standard buffer with $2 \mu \mathrm{M}$ Fura-2 AM. Data processing was carried out using Andor IQ 1.9 (Andor Technology, UK) and Matlab software (Matworks ${ }^{\circledR}$ ). All data are expressed as changes in the ratio of Fura-2 fluorescence at $340 \mathrm{~nm}$ and $380 \mathrm{~nm}$ against time $(\Delta$ $340 / 380)$, with the stationary calcium level set as 1 arbitrary unit, AU. Each experiment was repeated at least three times and data are expressed as means. For evoking calcium response $100 \mu \mathrm{M}$ UTP was used.

\section{RESULTS}

\section{Effect of $\mathrm{P}_{2} \mathrm{Y}_{2}$ receptor stimulation on MLC phosphorylation}

We found that phosphorylation of MLC induced by $\mathrm{P} 2 \mathrm{Y}_{2}$ receptor stimulation in cells with blocked ROCK correlated in time with actin cytoskeleton reorganization, leading to the recovery of normal cell morphology accompanied by F-actin redistribution and assembly of stress fibers. The level of P-MLC and cell morphology were compared in untreated control cells (Ctrl) and cells treated with the specific Rho-kinase inhibitor Y-27632 (Y). In both cases the cells were then treated with UTP (Ctrl UTP and Y UTP, see Materials and Methods). Before each experiment the ability of the cells to develop a calcium signal was checked using Fura ratiometry. Immunocytochemistry (Figs. 1, 2) and Western blot analysis (Fig. 3) were used to evaluate the level of phosphorylated MLC protein. Confocal microscopy imaging of immunoassayed cells was used for evaluation the fluorescent intensity of P-MLC staining (Fig. 1) and F-actin visualization in the same cells (Fig. 2). It is not surprising that ROCK inhibition reduces P-MLC level (Figs. 1f, 3 line 3), since active ROCK phosphorylates and inactivates MLC phosphatase and directly phosphorylates MLC (Amano et al., 1996; Kimura et al., 1996). Densitometry analysis of immunoblots showed a $65 \%$ decrease in the level of P-MLC in cells incubated with $100 \mu \mathrm{m} \mathrm{Y}-27632$ for $30 \mathrm{~min}$ as compared to untreated control cells (Fig. 3, line 3 and 1). After ROCK activity inhibiton actin cytoskeleton organization and the shape of normally polygonal and well spread glioma C6 cells were severely changed. Decreasing the level of P-MLC resulted in a loss of cell polarization, stress fiber decomposition and disappearance of lammellipodia. The cells rounded up and developed long outgrowths (Fig. 2f). F-

Figure 1. P-MLC distribution and amount in glioma C6 cells treated with different reagents

(a) Ctrl - control cells, (b) Ctrl UTP - cells stimulated with UTP, (c) Ctrl - $\mathrm{Ca}^{2+}$ UTP - control cells stimulated with UTP in calciumfree medium, (d) Ctrl $-\mathrm{Ca}^{2+}$ UTP $+\mathrm{Ca}^{2+}-$ cells fixed 2 min after addition of $\mathrm{Ca}^{2+}$ to calcium-free medium in which they were stimulated with UTP, (e) Ctrl ML-7 UTP - ML-7-pretreated cells stimulated with UTP, (f) Y - Y-27632-pretreated cells, (g) Y UTP - UTP stimulated Y-27632-pretreated cells, (h) Y $-\mathrm{Ca}^{2+}$ UTP - Y-27632pretreated cells stimulated with UTP in calcium-free medium, (i) $Y$ $-\mathrm{Ca}^{2+}$ UTP $+\mathrm{Ca}^{2+}$ - cells fixed 2 min after addition of $\mathrm{Ca}^{2+}$ to calcium-free medium in which Y-27632-pretreated cells were stimulated with UTP, (j) Y ML-7 UTP - Y-27632 and ML-7-pretreated cells stimulated with UTP. Diagram shows mean fluorescence intensity for 20 cells in each experimental group. Scale bar $20 \mu \mathrm{m}$. 

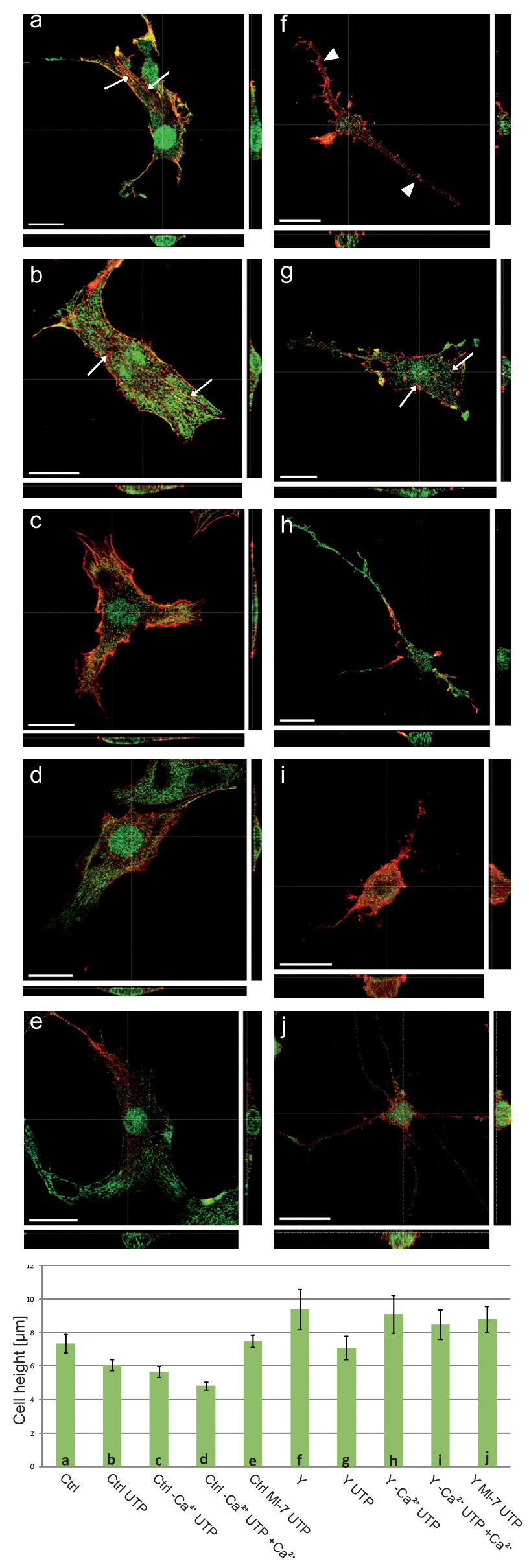

actin was concentrated mainly under the cell surface and in the elongated processes (Fig. 2f, arrowheads).

UTP stimulation induces MLC phosphorylation in control cells as well in those with inhibited ROCK (Figs. $1,3)$. Densitometry analysis of immunoblots showed a about $15 \%$ increase of phosphorylated MLC protein in UTP stimulated control cells (Fig. 3) compared to unstimulated control cells and an almost 160\% increase after UTP stimulation of cells pretreated with ROCK inhibitor (Fig. 3) compared to unstimulated cells pretreated with the inhibitor (Fig. 3). Immunocytochemical studies showed an increase of P-MLC level by a factor of four (compare Fig. 1f and g) 2 min after UTP treatment (see Materials and Methods). Activation of myosin II by $\mathrm{P}_{2} \mathrm{Y}_{2}$ receptor stimulation (Figs. 1, 3) did not cause visible changes in F-actin distribution or cell morphology of control cells. Nevertheless, the stimulated cells are more spread-out than the control ones as 3D images indicate (compare Fig. 2a, b). UTP stimulation of Y-27632pretreated cells led to the reorganization of actin cytoskeleton that enabled recovery from ROCK inhibition: change from rounded to polygonal shape, cell spreading, withdrawing of outgrowths and stress fiber assembly, however, only at the cell periphery (Fig. 2g, arrows).

Effect of MLCK activation on cell recovery from ROCK inhibition

Since MLCK is required for organization of peripheral stress fibers (Totsukawa et al., 2000; Katoh et al., 2001) we next investigated the effect of MLCK inhibition by ML-7 on MLC phosphorylation in cells with blocked ROCK. Inhibition of MLCK in glioma C6 cells does not affect cell morphology (Fig. 2e) or the level of PMLC in control cells (Fig. 1e). However, when MLCK is inhibited simultaneously with ROCK, stimulation of $\mathrm{P}_{2} \mathrm{Y}_{2}$ receptors, only caused a slight increase of P-MLC level (Fig. 1e), much smaller than in cells with inhibited ROCK only (Fig. 1g). This small increase of P-MLC level seems to be insufficient for acto-myosin cytoskeleton reorganization and cell shape recovery (Fig. 2j). It is suggested that in glioma C6 cells with inhibited ROCK, MLCK activation mediated by $\mathrm{G} \alpha_{\mathrm{q}}$-dependent calcium signal and subsequent MLC phosphorylation are necessary for acto-myosin interaction, cell morphology remodeling and assembly of stress fibers at the cell periphery.

\section{Effect of calcium signal on cell recovery from ROCK} inhibition

The UTP stimulation of glioma C6 cell $\mathrm{P} 2 \mathrm{Y}_{2}$ receptors initiates a typical store operated calcium signal (SOCE).

Figure 2. Immunofluorescence localization of phosphorylated MLC and F-actin in cells from Fig. 1

(a) Ctrl - control cells, (b) Ctrl UTP - cells stimulated with UTP, (c) Ctrl - $\mathrm{Ca}^{2+}$ UTP - control cells stimulated with UTP in calciumfree medium, (d) Ctrl -Ca ${ }^{2+}$ UTP $+\mathrm{Ca}^{2+}$ - cells fixed 2 min after addition of $\mathrm{Ca}^{2+}$ to calcium-free medium in which they were stimulated with UTP, (e) Ctrl ML-7 UTP - ML-7-pretreated cells stimulated with UTP, (f) Y - Y-27632-pretreated cells, (g) Y UTP — UTP stimulated Y-27632-pretreated cells, (h) Y $-\mathrm{Ca}^{2+}$ UTP - Y-27632pretreated cells stimulated with UTP in calcium-free medium, (i) $Y$ $-\mathrm{Ca}^{2+}$ UTP $+\mathrm{Ca}^{2+}-$ cells fixed 2 min after addition of $\mathrm{Ca}^{2+}$ to calcium-free medium in which Y-27632-pretreated cells were stimulated with UTP, (j) Y ML-7 UTP - Y-27632 and ML-7-pretreated cells stimulated with UTP. Orthogonal sections by confocal microscopy. Arrows - cortical network just beneath the plasma membrane and stress fibers. Arrowheads - F-actin in outgrowths. Scale bar $20 \mu \mathrm{m}$. 


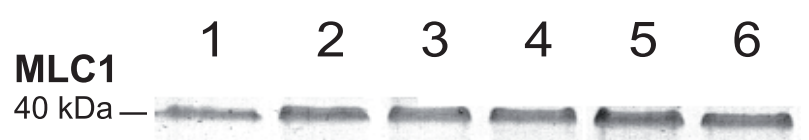

P-MLC

$20 \mathrm{kDa}-$

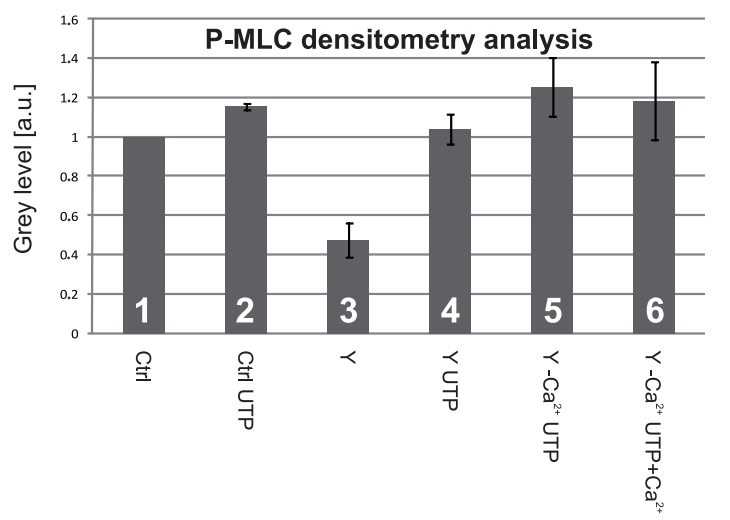

Figure 3. Level of P-MLC in glioma C6 cells under different experimental conditions

Ctrl - control cells (1), Ctrl UTP - cells stimulated with UTP (2), Y - Y-27632-pretreated cells (3), Y UTP — UTP stimulated Y-27632-pretreated cells (4), Y -Ca2+ UTP - Y-27632-pretreated cells stimulated with UTP in calcium-free medium (5), Y - $\mathrm{Ca}^{2+}$ UTP $+\mathrm{Ca}^{2+}$ - cells collected 2 min after addition of $\mathrm{Ca}^{2+}$ to calcium-free medium in which Y-27632-pretreated cells were stimulated with UTP (6). Representative immunoblot of P-MLC and average densitometry analysis of three experiments.

The increased MLC phosphorylation (Fig. 3 line 4) accompanying this signal temporally correlates with the recovery of the cells from ROCK inhibition. This effect occurs even though Y-27632 treatment affected the second phase of SOCE: capacitative calcium influx resulting from UTP-induced ER calcium store depletion (unpublished). However, when the UTP stimulation is performed in calcium-free medium and the calcium response is limited to $\mathrm{Ca}^{2+}$ release from intracellular stores, F-actin distribution and the morphology recovery do not take place (compare Fig. $2 \mathrm{~h}$ and g). Cells are unable to recover even though the level of P-MLC increases (Figs. 1, 3) and remains elevated during the next $10 \mathrm{~min}$ (not shown). Similar results were obtained when calcium-free medium was replaced 5 min after UTP stimulation with standard medium containing $2 \mathrm{mM}$ calcium and capacitative influx was recorded (Fig. 4). Under such conditions MLC phosphorylation takes place (Figs. 1, 3)

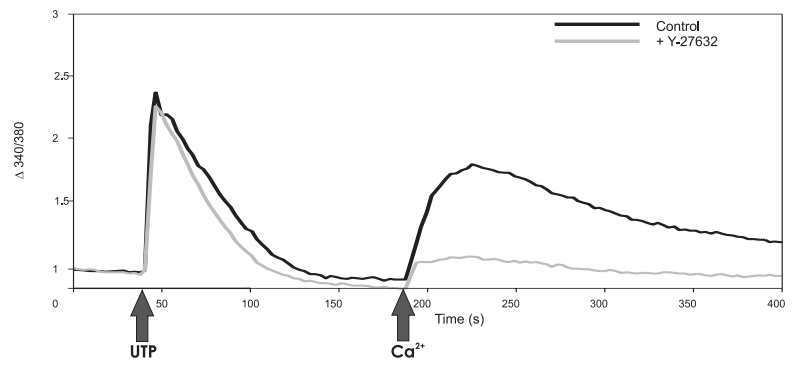

Figure 4. Biphasic calcium response of glioma C6 cells to UTP stimulation

Addition of UTP and $\mathrm{Ca}^{2+}$ is indicated by arrows. Grey line represents control cells, black line - cells pretreated with Y-27632. but it still is unable to cause actin cytoskeleton reorganization and renormalization of morphology in cells with inhibited ROCK (Fig. 2i). What is more, we found that MLC phosphorylation in both aforementioned cases led to cytoskeleton contraction what is manifested by cell spreading measured by 3D imaging (Fig. 2). These results indicate that MLC phosphorylation is essential but not sufficient for cells to recover from the effects of inhibition of ROCK activity.

\section{DISCUSSION}

Phosphorylation of MLC of myosin II plays a critical role in controlling acto-myosin contractility in smooth muscle and nonmuscle cells (Moussavi et al., 1993; Somlyo \& Somlyo, 2003). The actin-activated ATPase activity of myosin II is increased by phosphorylation of serine 19 of MLC (Moussavi et al., 1993). Myosin II and other actin-binding proteins downstream of the RhoA/ROCK signaling pathway are regulators of stress fiber and focal contact assembly. On the other hand, calcium mobilization mediated by $G \alpha_{\mathrm{q}}$ is known to promote actin cytoskeleton reorganization by triggering several signaling pathways, among others activation of calcium dependent myosin light chain kinase (MLCK).

Our results show that changes in the level of phosphorylated MLC in glioma C6 cells induced by ROCK inhibition and/or UTP stimulation correlate with dynamic actin reorganization and subsequent alterations in cell morphology. Myosin II inactivation in the presence of Y-27632 contributes to destabilization of the actin cytoskeleton. Since the F- to G-actin ratio is not affected under such conditions (Targos et al., 2006), the changes observed in actin cytoskeleton organization (stress fiber disappearance, relocation of F-actin) and in cell morphology seem to be caused by disorganization of the functional state of the acto-myosin II system by inhibition of Rho kinase. Dephosphorylation of MLC would favor myosin remaining in the low-affinity state for actin and subsequently dissociating from actin (Sutton et al., 2001). Figure $2 \mathrm{f}$ illustrates that phosphorylated myosin II diffuses all over the rounded cell body and does not colocalize with actin filaments concentrated in the long outgrowths appearing when ROCK activity is inhibited. The temporal separation between myosin II inactivation and full disruption of stress fibers (Sutton et al., 2001) suggests that other processes, such as actin severing, may be involved in stress fiber disassembly.

Myosin II phosphorylation and therefore its activation after UTP stimulation of the $\mathrm{G} \alpha_{\mathrm{q}}$-coupled $\mathrm{P} 2 \mathrm{Y}_{2}$ receptor in cells with inhibited ROCK occurs rapidly and correlates temporally with the assembly of short, weak stress fibers at the cell periphery (Fig. 2g, arrows). The localization of the stress fibers and the fact that it follows calcium mobilization indicate that $\mathrm{Ca}^{2+} /$ calmodulin dependent myosin light chain kinase (MLCK) may be responsible for the observed phosphorylation of MLC. This hypothesis is supported by the observation that MLCK inhibition by the specific inhibitor ML-7 almost completely prevented MLC phosphorylation in Y-27632treated cells (Fig. 1j). ROCK and MLCK may play distinct roles in the spatial regulation of MLC phosphorylation and subsequent myosin II activation. It has been shown that in cells with blocked ROCK and activated MLCK stress fibers are not assembled in the cell center (Totsukawa et al., 2000). The lower level of P-MLC observed in cells pretreated with Y-27632 even after UTP stimulation as compared to control cells seems to be due 
to constitutively active myosin II phosphatase which is normally inhibited by ROCK.

Apart from calcium, other upstream messengers may participate in the regulation of MLCK after $\mathrm{P} 2 \mathrm{Y}$, stimulation. Active Rac, for example, may inhibit MLCK at the cell leading edge (Sanders et al., 1999). The regulatory mechanism(s) could be complex and the activities of MLCK probably vary depending on cell types. The Rac/PAK signaling pathway may also be involved in regulation of MLC phosphorylation not only by controlling MLCK activity (Brzeska et al., 2004). Actin cytoskeleton reorganization can be triggered by UTP not only in a RhoA/ROCK-dependent manner.

Interestingly, we have found that changes in actin cytoskeleton dynamics and morphology of cells with inhibited ROCK, induced by $\mathrm{P}_{2} \mathrm{Y}_{2}$ receptor stimulation, depend on the presence of calcium in the medium, while we did not observe such a dependence for the level of phosphorylated MLC (Figs. 1, 2, 3). These results indicate that myosin II activation is only one of the regulatory mechanisms that are responsible for the morphological recovery of glioma C6 cells with inhibited ROCK to their native state. Our preliminary studies let us suggest that calcium-free medium influences activity of adhesion receptors and modifies signaling downstream of the $\mathrm{P} 2 \mathrm{Y}_{2}$ receptors.

Future analyses should be directed toward elucidating the upstream signaling cascades that regulate the actin cytoskeleton reorganization leading to the recovery of cells from ROCK inhibition.

\section{Acknowledgements}

This study was supported by a grant from the Ministry of Science and Higher Education, Poland (N N303 0179 33).

\section{REFERENCES}

Amano M, Ito M, Kimura K, Fukata Y, Chihara K, Nakano T, Matsuura Y, Kaibuchi K (1996) Phosphorylation and activation of myosin by Rho-associated kinase (Rho-kinase). J Biol Chem 271: 2024620249.

Arber S, Barbayannis FA, Hanser H, Schneider C, Stanyon CA, Bernard O, Caroni P (1998) Regulation of actin dynamics through phosphorylation of cofilin by LIM-kinase. Nature 393: 805-809.

Baranska J, Przybylek K, Sabala P (1999) Capacitative calcium entry. Glioma C6 as a model of nonexcitable cells. Pol J Pharmacol 51: 153-162.

Baranska J, Czajkowski R, Sabala P (2004) Cross-talks between nucleotide receptor-induced signaling pathways in serum-deprived and non-starved glioma C6 cells. Adv Enzyme Regul 44: 219-232.

Bernard O (2007) Lim kinases, regulators of actin dynamics. Int J Biochem Cell Biol 39: 1071-1076.

Berridge MJ (1995) Capacitative calcium entry. Biochem J 312: 1-11.

Bradford MM (1976) A rapid and sensitive method for the quantification of microgram quantities of protein utilizing the principle of protein-dye binding. Anal Biochem 72: 248-250.

Brzeska H, Szczepanowska J, Matsumura F, Korn ED (2004) Rac-induced increase of phosphorylation of myosin regulatory light chain in HeLa cells. Cell Motil Cytoskel 58: 186-199.

Chrzanowska-Wodnicka M, Burridge K (1996) Rho-stimulated contractility drives the formation of stress fibers and focal adhesions. $J$ Cell Biol 133: 1403-1415.

Clapham DE (1995) Calcium signaling. Cell 80: 259-268.

Czajkowski R, Baranska J (2002) Cross-talk between the ATP and ADP nucleotide receptor signalling pathways in glioma C6 cells. Acta Biochim Pol 49: 877-889.

Czajkowski R, Lei L, Sabala P, Baranska J (2002) ADP-evoked phospholipase $\mathrm{C}$ stimulation and adenyl cyclase inhibition in glioma C6 cells occur through two distinct nucleotide receptors, P2Y(1) and P2Y(12). FEBS Lett 513: 179-183.
Erb L, Liu J, Ockerhausen J, Kong Q, Garrad RC, Griffin K, Neal C, Krugh B, Santiago-Pérez LI, González FA, Gresham HD, Turner JT, Weisman GA (2001) An RGD sequence in the P2Y receptor interacts with $\alpha_{\mathrm{v}} \beta_{3}$ integrins and is required for $G_{0}$-mediated signal transduction. J Cell Biol 153: 491-501.

Erb L, Liao Z, Seye CI, Weismann GA (2006) P2 receptors: intracellular signaling. Eur J Physiol 452: 552-562.

Hartshorne DJ (1998) Myosin phosphatase: subunits and interactions. Acta Physiol Scand 164: 483-493.

Kawano Y, Fukata Y, Oshiro N, Amano M, Nakamura T, Ito M, Matsumura F, Inagaki M, Kaibuchi K (1999) Phosphorylation of myosin-binding subunit (MBS) of myosin phosphatase by Rho-kinase in vivo. J Cell Biol 147: 1023-1038.

Katoh K, Kano Y, Amano M, Onishi H, Kaibuchi K, Fujiwara K (2001) Rho-kinase-mediated contraction of isolated stress fibers. I Cell Biol 153: 569-583.

Kimura K, Ito M, Amano M, Chihara K, Fukata Y, Nakafuku M, Yamamori B, Feng J, Nakano T, Okawa K, Iwamatsu A, Kaibuchi K (1996) Regulation of myosin phosphatase by Rho and Rho associated kinase (Rho-kinase). Science 273: 245-248.

Maekawa M, Ishizaki T, Boku S, Watanabe N, Fujita A, Iwamatsu A, Obinata T, Ohashi K, Mizuno K, Narumiya S (1999) Signaling from Rho to the actin cytoskeleton through protein kinases ROCK and LIM-kinase. Science 285: 895-898.

Matsumura F (2005) Regulation of myosin II during cytokinesis in higher eukaryotes. Trends Cell Biol 15: 371-377.

Moussavi RS, Kelley CA, Adelstein RS (1993) Phosphorylation of vertebrate nonmuscle and smooth muscle myosin heavy chains and light chains. Mol Cell Biochem 127-128: 219-227.

Pak CW, Flynn KC, Bamburg JR (2008) Actin-binding proteins take the reins in growth cones. Nat Rev Neurosci 9: 136-147.

Putney JW Jr (1986) A model for receptor-regulated calcium entry. Cell Calcium 7: 1-12.

Riento K, Ridley AJ (2003) ROCK: Multifunctional kinases in cell behaviour. Nat Rev Mol Cell Biol 4: 446-456.

Sabala P, Czajkowski R, Przybylek K, Kalita K, Kaczmarek L, Baranska J (2001) Two subtypes of $G$ protein-coupled nucleotide receptors, $\mathrm{P} 2 \mathrm{Y}(1)$ and $\mathrm{P} 2 \mathrm{Y}(2)$ are involved in calcium signaling in glioma C6 cells. Br I Pharmacol 132: 393-402.

Sanders LC, Matsumura F, Bokoch GM, de Lanerolle P (1999) Inhibition of myosin light chain kinase by p21-activated kinase. Science 283: 2083-2085.

Sauzeau V, Le Jeune H, Cario-Toumaniantz C, Vaillant N, Gadeau A-P, Desgranges C, Scalbert E, Chardin P, Pacaud P, Loirand G (2000) $\mathrm{P}_{2} \mathrm{Y}_{1}, \mathrm{P} 2 \mathrm{Y}_{2}, \mathrm{P}_{2} \mathrm{Y}_{4}$, and $\mathrm{P} 2 \mathrm{Y}_{6}$ receptors are coupled to Rho and Rho kinase activation in vascular myocytes. Am J Physiol Heart Circ Physiol 278: H1751-H1761.

Schmitz AA, Govek EE, Bottner B, Van-Aelst L (2000) Rho GTPases: signaling, migration, and invasion. Exp Cell Res 261: 1-12.

Singh I, Knezevic N, Ahmmed GU, Kini V, Malik AB, Mehta D (2007) $\mathrm{Gd}_{\mathrm{q}}$-TRPC6-mediated $\mathrm{Ca}^{2+}$ entry induces RhoA activation and resultant endothelial cell shape change in response to thrombin. J Biol Chem 282: 7833-7843.

Somlyo AP, Somlyo AV (2003) $\mathrm{Ca}^{2+}$ sensitivity of smooth muscle and nonmuscle myosin II: modulated by $G$ proteins, kinases, and myosin phosphatase. Physiol Rev 83: 1325-1358.

Suplat D, Krzeminski P, Pomorski P, Baranska J (2007) P2Y(1) and $\mathrm{P} 2 \mathrm{Y}(12)$ receptor cross-talk in calcium signalling: evidence from nonstarved and long-term serum-deprived glioma C6 cells. Purinergic Signal 3: 221-230.

Suplat-Wypych D, Dygas A, Baranska J (2010) 2',3'-O-(4-benzoylbenzoyl)-ATP-mediated calcium signalling in rat glioma C6 cells: Role of P2Y nucleotide receptors. Purinergic Signal 6: 317-325.

Sutton TA, Mang HE, Atkinson SJ (2001) Rho-kinase regulates myosin activation in MDCK cells during recovery after ATP depletion. Am J Physiol Renal Physiol 281: F810-F818.

Targos B, Pomorski P, Krzemiński P, Barańska J, Rędowicz MJ, Kłopocka W (2006) Effect of Rho-associated kinase inhibition on actin cytoskeleton structure and calcium response in glioma C6 cells. Acta Biochim Pol 53: 825-831.

Totsukawa G, Yamakita Y, Yamashiro S, Hartshorne DJ, Sasaki Y, Matsumura F (2000) Distinct roles of ROCK (Rho-kinase) and MLCK in spatial regulation of MLC phosphorylation for assembly of stress fibers and focal adhesions in 3T3 fibroblasts. J Cell Biol 150: 797-806.

Tsuji T, Ishizaki T, Okamoto M, Higashida C, Kimura K, Furuyashiki T, Arakawa Y, Birge RB, Nakamoto T, Hirai H, Narumiva S (2002) ROCK and mDia1 antagonize in Rho-dependent Rac activation in Swiss 3T3 fibroblasts. J Cell Biol 157: 819-830.

Worthylake RA, Lemoine S, Watson JM, Burridge K (2001) RhoA is required for monocyte tail retraction during transendothelial migration. J Cell Biol 154: 147-160. 